
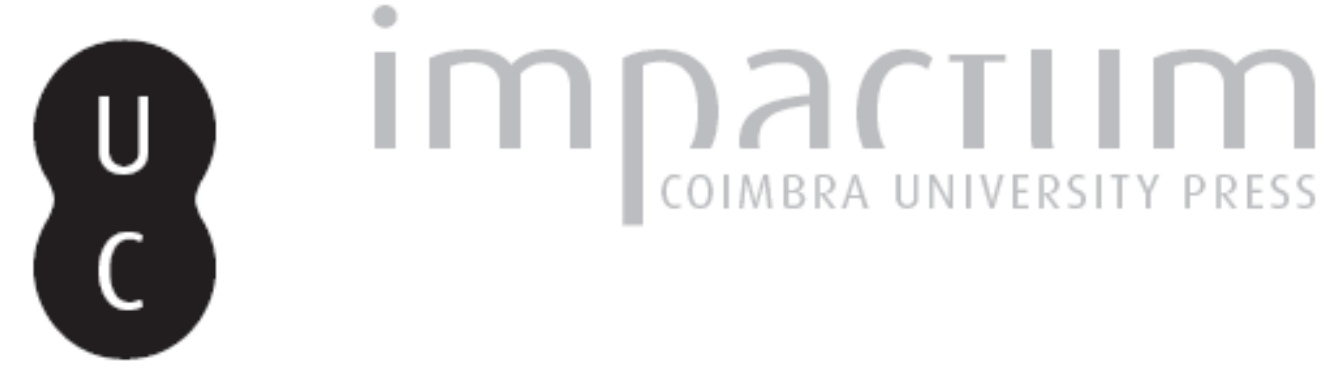

\title{
António Sérgio leitor de Nobre: do «modelo moral de uma comunidade» [Herculano] ao «puro racionalismo historiante e imperial» [Nobre]
}

Autor(es): $\quad$ Barreira, Cecília

Publicado por: Imprensa da Universidade de Coimbra

URL persistente:

URI:http://hdl.handle.net/10316.2/45047

DOI:

DOI:https://doi.org/10.14195/2183-8925_5-1_8

Accessed : $\quad$ 26-Apr-2023 12:54:04

A navegação consulta e descarregamento dos títulos inseridos nas Bibliotecas Digitais UC Digitalis, UC Pombalina e UC Impactum, pressupõem a aceitação plena e sem reservas dos Termos e Condições de Uso destas Bibliotecas Digitais, disponíveis em https://digitalis.uc.pt/pt-pt/termos.

Conforme exposto nos referidos Termos e Condições de Uso, o descarregamento de títulos de acesso restrito requer uma licença válida de autorização devendo o utilizador aceder ao(s) documento(s) a partir de um endereço de IP da instituição detentora da supramencionada licença.

Ao utilizador é apenas permitido o descarregamento para uso pessoal, pelo que o emprego do(s) título(s) descarregado(s) para outro fim, designadamente comercial, carece de autorização do respetivo autor ou editor da obra.

Na medida em que todas as obras da UC Digitalis se encontram protegidas pelo Código do Direito de Autor e Direitos Conexos e demais legislação aplicável, toda a cópia, parcial ou total, deste documento, nos casos em que é legalmente admitida, deverá conter ou fazer-se acompanhar por este aviso.

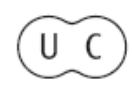




\section{REVISTA DE HISTÓRIA DAS IDEIAS 5}

\section{António Sérgio}

*

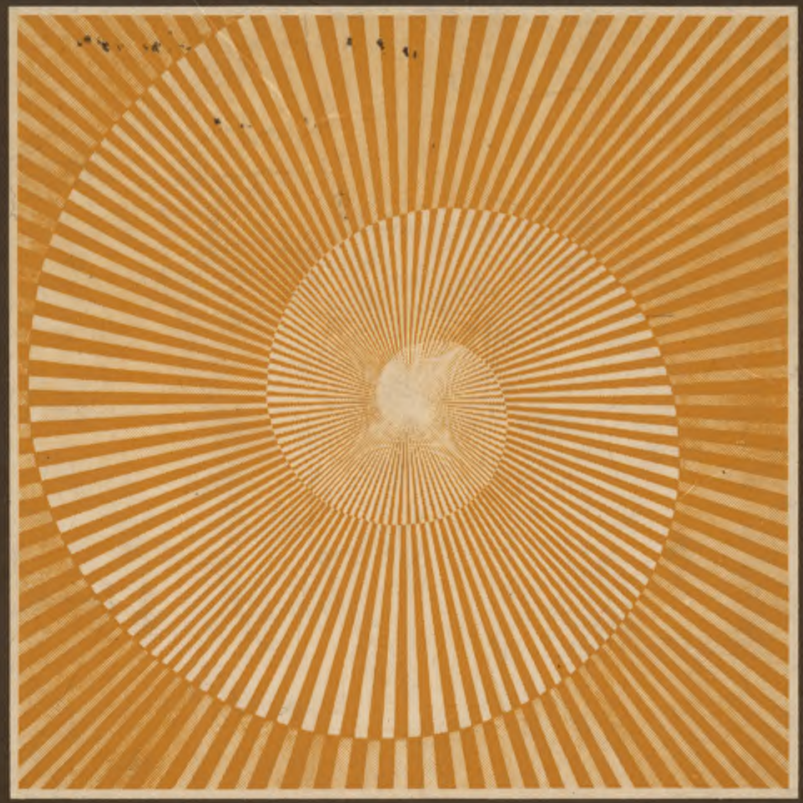

INSTITUTO DE HISTÓRIA E TEORIA DAS IDEIAS FACULDADE DE LETRAS 


\title{
ANTÓNIO SÉRGIO LEITOR DE NOBRE
}

\author{
Do «modelo moral de uma comunidade)) [Herculano] \\ ao «puro racionalismo historiante e imperial)) [Nobre]
}

Sérgio enfileira com os maiores pensadores que reflectiram sobre os grandes traumas nacionais, ao trazer, para o forum dos debates públicos, temas que nunca tinham sido filtrados ou localizados no fácies polémico que o autor dos Ensaios lhes confere. Partamos para a consideração das temáticas sergianas senão com a mesma fundura crítica, o que é sobremaneira difícil de concretizar dada a genialidade com que aquelas foram discernidas, pelo menos com a objectividade de quem sabe não possuir o segredo das verdades universais ou a megalomania das respostas científicas, logo, rigorosas. Porque o rigor não é mais hoje, uma apoteose do discurso racional, mas uma apetência do pensamento coerente e lógico.

A cultura representa um esforço no sentido da transfiguração da sensibilidade e de gosto. Daí, simultaneamente, a sua perfídia e a sua candura, o seu reencontro sempre englobalizante com as coisas, os objectos, os imaginários os mitos. Não mais será possível separar o olhar que se estende sobre um panorama cultural de uma desinocência primeira que preside a todo e qualquer juízo de valor.

Sérgio escudava-se quase sempre numa objectividade aparentemente inapelável e irreprimível, articulando, num fio discursivo fluido e transparente, num ascetismo diletante a custo reprimido, uma teia de raciocínios congeminados para um fim. Um fim simuladamente desideológico, isto é, de tal modo decorrente duma harmonia de arrazoados que se gratificava, ele próprio, numa evidência. Tomar as coisas evidentes sob determinado ponto de vista, o seu confessemo-lo des-

\footnotetext{
* Faculdade de Ciências Sociais e Humanas da Universidade Nova de Lisboa.
} 
de já: eis a mestria de um espantoso manobrador das ideias, de um kantista que nunca se refez das leituras hegelianas, apaixonadamente assimiladas mas de algum modo relegadas para um plano secundarizado face ao filósofo da Crítica da Razão Pura. Ainda Pascal, também Descartes: estes quadravam-se maravilhosamente ao espírito de Sérgio. A dúvida serena, resolúvel na sua dilemática primordial, é a que mais lhe agrada. Porque a dúvida só interessa na mundovisão sergiana enquanto veiculadora no incauto leitor dessa tensão rumorosa que antecede o «Eurêka» descobridor. Contudo, mesmo estas etapas gnoseológicas são-nos sugeridas por Sérgio. Não nos admiremos: Sérgio é assim mesmo. Lança os dados, permite a arrogância da dúvida metódica, mas, por fím, lá nos conduz, através dum sinuoso caminho de minudências estupendamente lúcidas, à meta previamente rasurada no seu espírito. Assim, as consciências mais exigentes encontram uma pacificação que de outro modo não forjariam.

Passemos, então, ao Sérgio leitor de figuras gradas da nossa literatura: e é nesta maleabilidade feita de aparentes imprevistos (Sérgio nunca se diz especialista seja em que matéria for; parte para as pugnas ideológicas ou científicas como um leigo assumido. Daí a «inocência» das suas perplexidades, a credibilidade dos seus juízos, proferidos distanciada e cornedidamente, perfilhados apenas por serem autênticos, não tutelados em enviesadas tessituras de preconceitos) que, permanentemente, constrói e destrói mitos na historiografia, na filosofia, na literatura, na ciência, etc., etc. Porque Sérgio diz-se ensaísta, e é-o sem a menor sombra de dúvida e com que habilidade retórica, dado que no fundo teria vergonha de confessar o desejo de reincarnação do enciclopedismo setecentista, racional, profundo e perfeito, que muito o seduziria decerto.

O ensaísta que ia vibrando «golpes de malho em ferro frio» consoante as grandes vagas polémicas que assolavam o mediano panorama cultural português, gosta de ir contra a corrente, mesmo que ao desvendar episódios e teorias, fira medularmente uma figura histórica, um ficcionista, um poeta, uma época, uma interpretação, um modo de explicação do mundo. E na cegueira da irreverência crítica não poupa nada, exceptuando a galeria de heróis que se habituara a prezar como nacionais. Na fila daqueles que se destinam ao cemitério do anonimato perpétuo lá se contam um Teófilo, um Guerra Junqueira, um António Nobre, um Pascoaes e tantos, tantos outros. No camarote dos eleitos pontua Herculano, grande figura moral. Antera também tem assento no dito camarote. E ombreia com Herculano enquanto grande exemplo 
de virtude, civismo e moralidade irrepreensíveis. Não importa saber se Antero era ou não um poeta de rara qualidade: era-o, sem dúvida, dado o perfil das suas qualidades éticas. Nem sequer exageramos: Sérgio pautava as suas simpatias ou antipatias viscerais consoante os padrões morais e/ou ideológicos que regiam as personagens. Daí a tibieza de algumas das suas análises, mesmo quando brilhantemente cercidas num estilo literário inconfundível, numa argúcia de meios invejável.

A geração de 90, alcunhada de nacionalista, absorvida por sectores retrógrados do salazarismo como ideologia conforme ao regime, não poderia deixar em Sérgio senão um vago sabor a mediocridade e periculosidade, estranhamente associadas numa romagem de teor reaccionário. Sérgio antifascista reagia contra os estigmas ideológicos do regime. Sentimentalmente percebemos, aceitamos, acatamos. As nossas opções políticas, contudo, não deveriam intrometer-se na análise das obras de arte. Não que a Arte se dilua num amorfismo acefálico face à sociedade que lhe perspectiva um horizonte semântico. Mas porque a Arte, mesmo quando se exprime em palavras ou imagens, representa uma instância autónoma nas discursividades que assolam o quotidiano dos indivíduos. Isto é, a poesia, a prosa ficcionada não podem ser assimiladas a um nível de coloquialidade chão e unívoco. Sérgio lê ideologicamente a literatura, na unicidade reducionista da mensagem que se apreende, fácil, demasiadamente dúctil. Sérgio lê politicamente as obras do século XIX, à luz dos condicionalismos que o salazarismo impunha, enquanto sistema autoritário.

É lógico que Sérgio não foi o único que operou leituras intencionadas, veladamente inobjectivas. Trata-se, antes, de desenterrar figuras injustamente esquecidas, na nossa modesta opinião. Trata-se de oxigenar o sergianismo, de lhe devolver a capacidade crítica que sempre lhe fora apanágio e razão de ser.

Resumamos a posição de Sérgio face ao melancólico poeta do Só:

«Como se vê (e discuto-o porque tudo isso foi tomado a sério) é o puro nacionalismo historiante e imperial,- megalómano, guerreiro, reaccionário, passadista, retórico, - do intelectual aliteratado português moderno, que nos vem perguntar, sebastianisticamente:

que é dos sonhos de glória e de ambição?; 
desse que navega no seu próprio quarto, ou comodamente instalado num bom paquete, mas que declama com ênfase:

sou neto de Navegadores,

Heróis, Lobos d'âgua, Senhores

da Índia, d'Aquém e d'Além-mar!

reservando para a plebe, no seu devanear de fidalgote, de folclorista, de snob, o papel de esmolar-lhe uma sopinha à porta:

O sino da igreja tooava, à tardinha:

Que tristes seus dobres!

Era a hora em que eu ia provar, à cozinha,

$O$ caldo dos pobres...» 0).

Mas, note-se, o ensaísta previne os eventuais contraditores quanto à crítica literária que, no seu entender, não estaria em causa:

«Pois que também no caso do autor da Pátria não foi crítica literária o que eu tive em mira, mas sim sociológica; ou, antes: um estudo de psicologia da orientação mental, tal como se revela em suas várias obras, encaradas à luz das relações com a Grei.........Como por aí se está vendo, foram sociais-psicológicos os problemas que eu pus; foram talvez filosóficos; foram decerto políticos; foram pedagógicos; foram, enfim, sociais: e de maneira nenhuma problemas estéticos, problemas de crítica de literatura» $\left({ }^{2}\right)$.

Interessante esta posição defensiva cuja originalidade, no nosso entender, se posiciona na associação, pouco corrente ao tempo em que eram redigidos os Ensaios, dos problemas sociais com a perspectiva psicológica. Assinale-se ainda a particularidade: Sérgio opinante de temáticas literárias diz-se sobretudo sociólogo. O que lhe autoriza de um modo simples e impositivo uma atitude objectiva que o especialista literário provavelmente não poderia assumir.

Aliás, nas Notas de Literatura Portuguesa inseridas no Tomo III dos Ensaios não é por acaso que se lança magnificamente a figura moral de Alexandre Herculano, antes de se analisar a célebre carta herculaniana dirigida a José Fontana àcerca das Conferências do Casino. Em torno daquilo que

O António Sérgio, Ensaios I, Lisboa, Sá da Costa, 1976, p. 15. (') Idem, ob. cit., p. 17. 
considera a "figura típica», "modelo moral de uma comunidade» Sérgio evidencia, uma vez mais, uma das obsessões do seu trajecto de ideais e normas de vida: a assumpção de grandes heróis da contemporaneidade cujas sombras tutelares projectem nos coevos e, nele próprio, António Sérgio de Sousa Júnior, o fantasma de uma paternidade ideológica, a vibração de uma herança que se transmite e se recebe. Sérgio detesta a orfandade cultural: talvez a receasse, sobremaneira. Ele que destruiu mitos, como nenhum outro vulto da nossa cultura jamais o fizera, temia, afinal, que no seu exemplo de homem que não dava tréguas à mediocridade e à apatia mentais, se não filiasse no exemplo de outros. A ausência, o vazio constam nas fobias sergianas apreensíveis, apenas, a um nível inconsciente. Deste modo Herculano reúne as condições para se legitimar Pai do sempre solitário Sérgio nas suas pugnas de alcance nacional. Severidade de carácter, ombridade, estoicismo: eis os traços que relevam em Herculano e lhe asseguram junto do ensaísta uma admiração, uma identificação velada, nunca reclamada, sejamos justos. Herculano é o modelo: a ele se oporiam os nacionalistas, assim alcunhados, da geração de 90:

«Que solução política há no António Nobre, extraída e exaltada pelos seus sequazes? Há alguma? Há; e vem a ser a seguinte:

"Que El-Rei menino não tarda a surgir,

Que ele há-de vir, há-de vir, há-de vir!» ( $\left.{ }^{3}\right)$.

$\ddot{\mathrm{E}}$ um pouco a talhe de foice que irrompe o exemplo herculaniano. Ora repare-se:

«Sentem-se esses literatos a representar o povo, e como tais se nos dão: porém, o povo de pescadores e de trabalhadores campónios, se não fosse o ignaro pobretão que ele é - e por isso pitoresco para os senhores do historismo, apreciadores do folclore, - sentir-se-ia representado por um Alexandre Herculano» $\left({ }^{4}\right)$.

A postura do autor dos Ensaios face à cultura portuguesa lembra a do pai sabedor que absolverá o filho, após anos e anos de vida debochada e inútil, caso siga à minúcia a terapêutica recomendada pelo progenitor. $O$ pedagogo arroga-se o direito de aconselhar quais as vias, os trilhos por onde se deverá prosseguir; quando o pedagogo não legitima uma au-

(3) Idem, ob. cit., p. 14

(4) Idem, ob. cit., p 15. 


\section{Antonio Sérgio}

toridade moral suficiente, então, entra em cena o sociólogo da cultura que com a exactidão do cientista e do matemático explica o porquê das coisas e lhes prescreve um perfil e um itinerário. Caso o sociólogo não seja suficiente para filtrar a complexidade do fenómeno, não repugna a Sérgio firmar-se como historiador, economista, filósofo ou epistemólogo avant la lettre. Sistema de tal modo unificador e englobalizante, a mundovisão sergiana, que se vocaciona numa missão épica, de salvação nacional.

Não nos reservamos aqui o contradizermos os argumentos do Sérgio que leu António Nobre, ou Teófilo Braga, ou Oliveira Martins, ou Teixeira de Pascoaes. O que nos interessa será evidenciar um modo de produção das ideias. Desde logo, algumas conclusões se nos afiguram pertinentes enunciar: todo o texto literário, para Sérgio, preenche um espaço ideológico politicamente identificável. $O$ papel do crítico, aquele cuja função de pedagogista se sobrepõe à do especialista literário, será o de tomar transparente o veio ideológico que subjaz a qualquer texto. Mas não só: deverá diagnosticar-lhe os males pelos quais se encontra (ou não) enfermo, não enquanto texto literário, mas enquanto portador de uma voz ideológica. A Cultura devolve-se a público, sobretudo, num corpo de concepções e de praxis éticas e os seus arautos ou se postulam no quadro de uma moralidade sã, escorreita, cívica ou incorrem numa má intencionalidade fundamental face ao colectivo. A elite cultural de uma comunidade deverá ser a mais perfeita, a mais dinâmica até pelo papel que naturalmente lhe impende de educadora dos restantes extractos sociais (confronte-se a ideia de elite em Ortega y Gasset, curiosamente nascido no mesmo ano de António Sérgio, 1883, e cujo centenário igualmente se comemora no país vizinho; e em Gramsci, cuja categoria de intelectual orgânico permite uma identificação, mesmo que deformada, com algumas teorias sergianas).

Sergio cumpre a missão de pedagogo/médico/salvador dos nossos males nacionais: e nessa "catársis» reparadora que o ensaísta opera através dos seus diagnósticos pessimistas como que assume e desempenha o papel providencialista que gerações de portugueses lhe reclamavam (reclamam).

Não existe espaço para o sonho na gnoseologia sergiana. É a racionalidade que preside ao fluir do pensamento humano. Pois a Razão, quando espraiada na sua magnanimidade, é objectiva e transparente e não espelha a dúvida corroídora.

Questionemos a vasta e fecunda obra de Sérgio porque ela ainda só parcialmente nos remeteu respostas: que as dúvidas - que naturalmente nos colocamos ao interrogarmo-nos, 
enquanto comunidade com um perfil histórico muito individualizado, sobre o nosso querer?desejar na trifuncionalidade passado/presente/devir - passem por um redimensionamento das obras dos nossos maiores pensadores. De Camões a Pessoa. De Vieira a Sérgio. De Camilo a Agustina. Que, afinal, no entrecruzamento dos imaginários que reproduzimos e recriamos no nosso quotidiano, haja lugar para o sonho e para a utopia. Com um Sérgio ao alcance de todos. Também. 